\title{
Editorial
}

\section{Connect, Collaborate, Innovate}

\section{Cowin AJ and Tehan P}

For referencing Cowin AJ and Tehan P. Connect, Collaborate, Innovate. Wound Practice and Research $2021 ; 29(2): 65$.

DOI https://doi.org/10.33235/wpr.29.2.65

Connect, Collaborate, Innovate was the theme for this year's Wounds Australia National conference which was held virtually earlier this year. Little did the organisers know, when planning of the conference began in 2018, that a global pandemic would ensue, changing our lives forever. The delivery of the conference itself would have to reflect the theme, using innovative technology to deliver an online experience to allow us to connect and collaborate. An advantage of the online delivery of the conference was that wound practitioners from across Australia were able to attend without having to travel, taking away rurality as a potential barrier for attendance. Despite ongoing COVID restrictions, over 650 participants were still able to connect with colleagues, industry and experts and learn about the latest developments in clinical practice, theory and research. Through the various rooms within the virtual meeting place, participants were able to collaborate with new and old connections to solve problems and share innovations and hopefully everyone was inspired to develop and implement new innovations in their own wound practice. The feedback from the delegates has been overwhelmingly positive, with many commenting on the diverse, inter-disciplinary, international, innovative and sophisticated program reflective of our maturing organisation.

In a first for Wounds Australia and Wound Practice and Research we are proud to be able to publish the many excellent abstracts that were presented either as an oral presentation or as a poster during the conference in this issue of the journal. These 55 national and international abstracts show the breadth of research, innovation and engagement that is currently being undertaken to improve wound care around Australia and beyond and are a must read for everyone who was unfortunately unable to attend the conference this year.

Prof Allison J Cowin

Editor Wound Practice and Research

Dr Peta Tehan

Associate Editor Wound Practice and Research
We were also pleased to announce the winners of the Coloplast Literary awards for 2020 during the conference program. These three categories of awards were judged independently and taking conflicts of interest into account by WPR's editorial board with a focus on significance, originality, presentation and conclusions. We were delighted to present the winners with their awards of $\$ 1000$ as well as the runners' up with their certificates during the conference.

\section{Original research article}

Winner - Fiona Coyer and colleagues: Maintaining skin health and integrity for staff wearing personal protective equipment for prolonged periods: a practical tip sheet.

Runner-up - Emily Haesler and Keryln Carville: Implementing the 2019 International Guideline: consultation on barriers, facilitators, challenges and resource needs.

\section{Literature review/clinical practice}

Winner - Hanif Haidari and colleagues: Silver-based wound dressings: current issues and future developments for treating bacterial infections.

Runner up - Larelle Upton: What is the effect of age on wound healing in the acute trauma setting? A scoping review.

\section{Case study/series}

Winner - Bonnie Fraser: Chronic hepatitis C-related cryoglobulinaemic vasculitis manifesting as non-healing skin ulcers: a case presentation.

Joint runners up - Yasantha Rajapakse and Glen Hawkins: Hyperbaric oxygen therapy in the treatment of radiation-induced wound complications of breast cancer. Collen O'Brien-Malone and colleagues: Using seating and restricted pelvic position to improve patient functional outcomes post sarcoma removal: a case study.

We thank all the authors for submitting their important research to Wound Practice and Research and look forward to future submissions that continue to connect, collaborate and innovate.

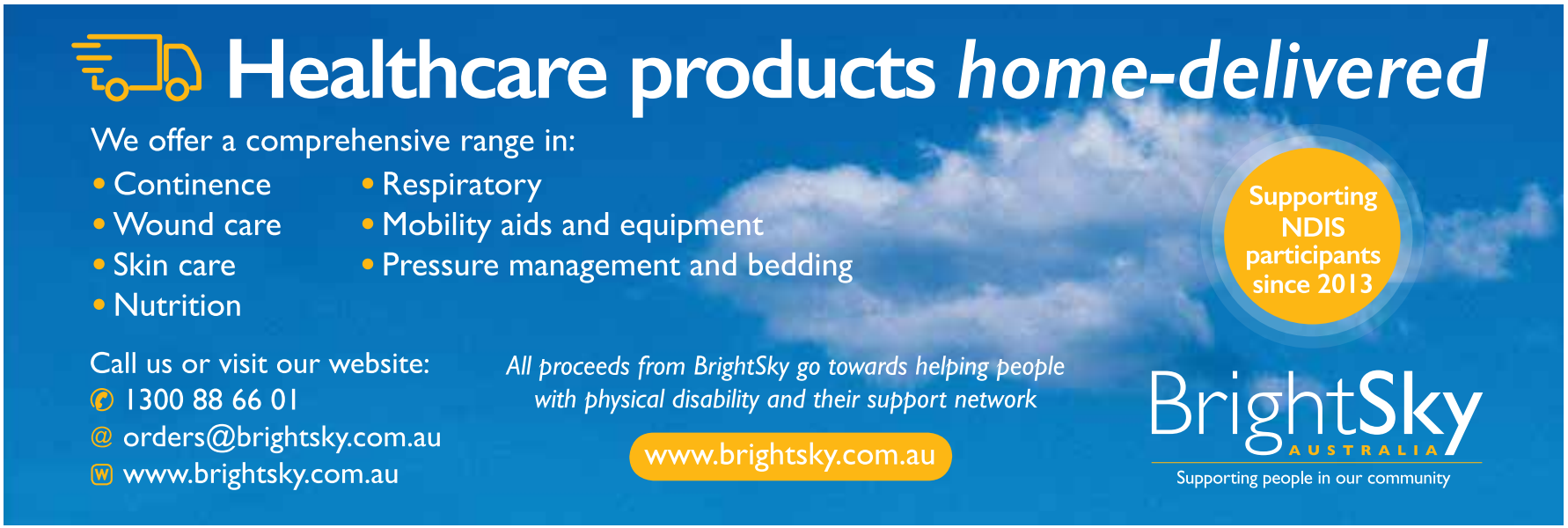

